\title{
Overview of hyperspectral remote sensing for mapping marine benthic habitats from airborne and underwater sensors
}

\author{
Heidi M. Dierssen* \\ University of Connecticut, Marine Sciences/Geography, 1080 Shennecossett Rd, Groton, \\ CT, USA 06340
}

\begin{abstract}
The seafloor, with its diverse and dynamic benthic habitats varying on meter to centimeter scales, is difficult to accurately monitor with traditional techniques. The technology used to build imaging spectrometers has rapidly advanced in recent years with the advent of smaller sensors and better signal-to-noise capabilities that has facilitated their use in mapping fine-scale benthic features. Here, the use of such sensors for hyperspectral remote sensing of the seafloor from both airborne and underwater platforms is discussed. Benthic constituents provide a so-called optical fingerprint with spectral properties that are often too subtle to be discerned with simple color photographs or multichannel spectrometers. Applications include the recent field validation of the airborne Portable Remote Imaging SpectroMeter (PRISM), a new imaging sensor package optimized for coastal ocean processes in Elkorn Slough California. In these turbid sediment-laden waters, only subtle spectral differences differentiate seafloor with sediment from that with eelgrass. The ultimate goal is to provide robust radiometric approaches that accurately consider light attenuation by the water column and are able to be applied to diverse habitats without considerable foreknowledge.
\end{abstract}

Keywords: Hyperspectral remote sensing, coastal mapping, ocean optics, PRISM

\section{INTRODUCTION}

Traditional methods for characterizing the seafloor or benthos involve underwater assessments using photography, video or diver surveys. Such methods are often qualitative in scope, have limited spatial scales, and require considerable human interpretation of the primary seafloor features. Another common method involves aerial photography from aircraft using a simple camera system that measures light reflected from the water in three primary wavebands: red (R), green (G), and blue (B) or an RGB image. This simulates our human eye which has so-called RGB photoreceptor cells (cones with peak absorbance at 564, 534 and $420 \mathrm{~nm}$ ) allowing for human trichromatic color vision [1]. Digitizing features from photographs can be painstaking and subjective work and often the primary features must be known in advance. Beds of seagrass, for example, absorb visible light for photosynthesis and make the image look darker to the eye, but such dark patches may be due to other types of seafloor or "benthic" habitats including dense macroalgae, sediment with biofilm, or even light-absorbing compounds in the water column like phytoplankton or gilven (colored dissolved organic matter) [2].

New sensors and techniques based on imaging spectroscopy have been developed to assess the spectral signature of benthic features on the seafloor. Deployed from satellites and airplanes, these sensors can detect the full spectrum of light being emitted from the sea surface and have advanced coastal habitat mapping from seagrasses to coral reefs over the last decade [3-6]. Multi-channel remote sensing can be useful in mapping clear coastal banks and bays [2], but hyperspectral remote sensing provides a more detailed spectral fingerprint that can then be used to assess the water column properties and potentially the depth and color of the seafloor when the water is "optically shallow" and photons reflected from the seafloor can be detected at the sea surface $[7,8]$.

Sensor technology has improved dramatically in recent years and new imaging spectrometers are better able to discriminate dark coastal waters where water-leaving radiance only contributes a few percent of the total light detected at

*heidi.dierssen@uconn.edu; phone (860)405-9239; fax (860)405-9153; colors.uconn.edu

Imaging Spectrometry XVIII, edited by Pantazis Mouroulis, Thomas S. Pagano, Proc. of SPIE Vol. 8870, 88700L · @ 2013 SPIE · CCC code: 0277-786X/13/\$18 · doi: 10.1117/12.2026529 
the sensor. A majority of the signal arises from light scattered within the atmosphere and off the sea surface as glint and must be eliminated through a complex process called "atmospheric correction" $[9,10]$. Such sensors can be uniquely tailored to the coastal environment with high signal-to-noise, large dynamic range enabled by rapid readout and high throughput, low polarization sensitivity, broad spectral coverage (350-1050 nm with additional $1240 \mathrm{~nm}$ and $1610 \mathrm{~nm}$ channels), high spectral cross-track and IFOV uniformity ( $>90 \%)$, and high radiometric calibration accuracy [11].

Imaging spectrometers have also been deployed on underwater vehicles to image the dark depths of the seafloor that are outside the limits of passive remote sensing techniques [12]. Such imaging generally occurs within meters of the seafloor, with external light sources, and can be conducted from remotely operated vehicles (ROVs) that are tethered below a ship or autonomous underwater vehicles (AUVs) with their own power and navigation capabilities. Propellerdriven AUVs have enough payload for hyperspectral imaging and light systems and can sample over large distances without the constraints of a tether and ship-based crew. Imaging from ROVs and AUVs provide a method for discriminating benthic features at depth in the ocean and can be used to map both man-made objects such as pipelines and deep-living organisms such as cold corals.

\section{SPECTRAL FINGERPRINTS}

Benthic features from minerals to seagrass absorb and reflect different portions of the visible spectrum giving them unique spectral "fingerprints." These spectral fingerprints can be used to distinguish features that are not easily distinguished with simple color photography. In a coral reef environment, for example, the spectra from many different benthic features can be easily discriminated with peaks and dips across the visible spectrum (Fig. 1). Benthic reflectance is measured as the fraction of incident light reflected back from a target and are the inherent colors of the benthic constituents independent of the light illuminating them. A white feature would be spectrally flat across all visible wavelengths, but it might appear blue underwater in tropical ecosystems where blue photons dominate the incident light field. Hence, benthic reflectance is more than just the color reflected from the seafloor and requires an assessment of the incident downwelling light (either sunlight or an external light source).

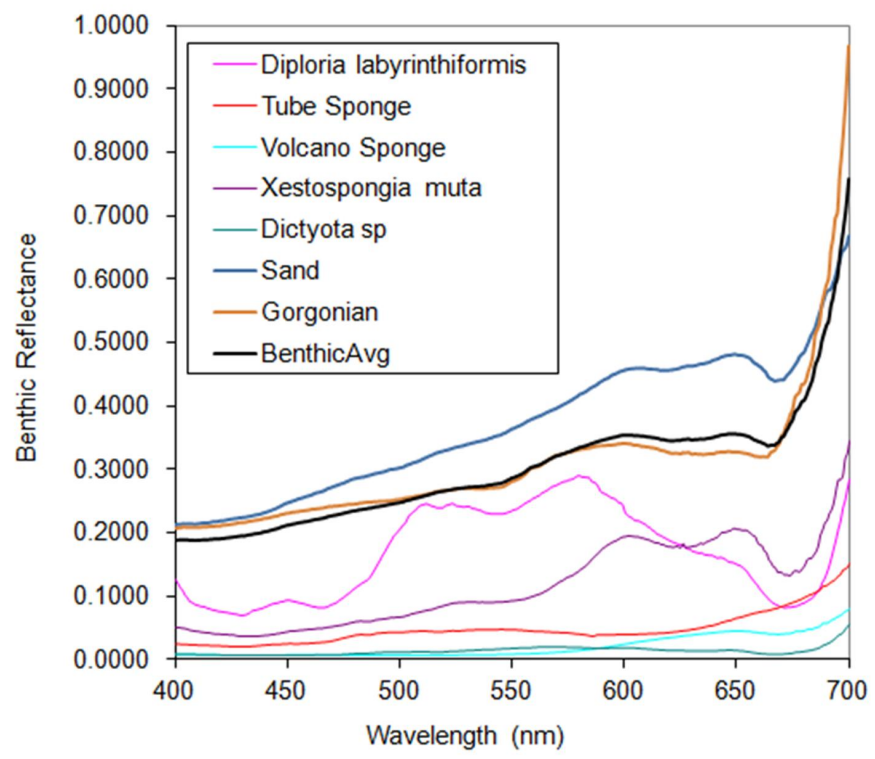

Figure 1. Benthic reflectance spectra across the visible spectrum obtained within a coral reef ecosystem in the Greater Florida Keys in January 2011. See Video http://www.youtube.com/watch?v=SyptXFWmZKM 
In addition, the benthic reflectance signal reaching a sensor on any platform (satellite, aircraft, ship or ROV) is distorted by the intervening water column. Pure water absorbs primarily in the red to near infrared portions of the signal, but natural seawater contains compounds such as phytoplankton, colored dissolved organic matter, and suspended sediments that differentially absorb and scatter portions of the visible spectrum altering the signal detected remotely [10]. Primarily blue and red photons are absorbed by the water column and the resulting reflectance spectrum at the sea surface appears significantly altered, generally greener $(500-600 \mathrm{~nm})$, than the benthos. When comparing spectra obtained in the same water clarity and depth, the amount of signal can vary due to the reflectivity of the seafloor. Bright sands will reflect more light than seafloors with seagrasses and macroalgae that absorb light for photosynthesis (Fig. 2[2]). Sediment biofilms (e.g., "Grapestone" sediment in Fig. 2B) contain photosynthetic microalgae that similarly reduce reflectivity. A spectral dip at $665 \mathrm{~nm}$ is commonly attributed to absorption by chlorophyll due to photosynthetic organisms and can be observed in most sediment spectra. The increasing reflectance in the near infrared is rapidly absorbed by water molecules and only reaches the sea surface in shallow and relatively clear waters.

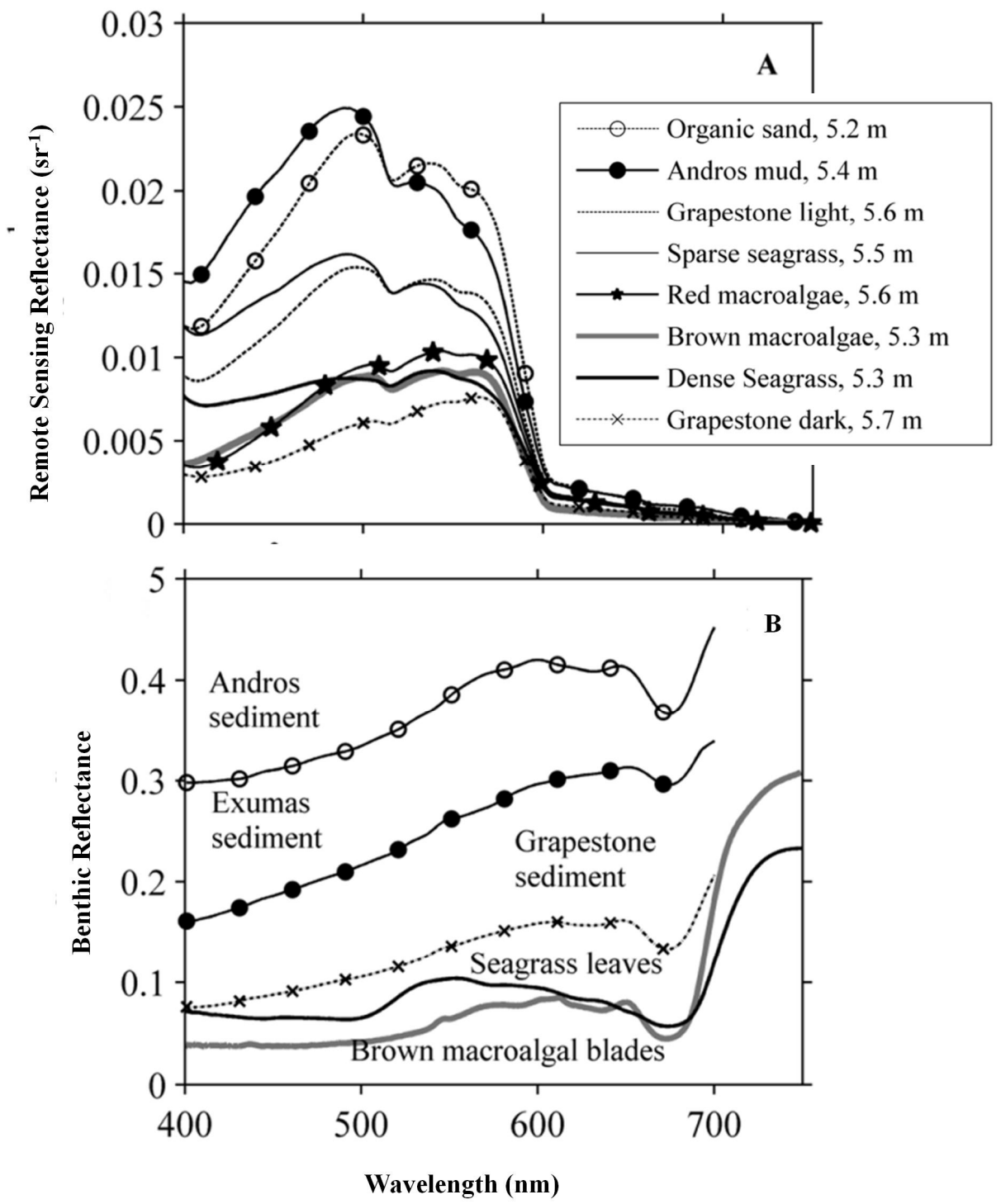

Figure 2. A) Remote sensing reflectance measured in the field over different benthic substrates with $\sim 5 \mathrm{~m}$ water depths in clear Bahamian waters. B) Benthic reflectance spectra for sediment, seagrass and brown macroalgal blades from the same region. Data reproduced from [2] 
An aircraft or satellite measures radiance derived from four different streams, as shown in Fig. 3. The aquatic remote sensing community uses the term "Remote Sensing Reflectance" or Rrs to describe the water color at the sea surface and to differentiate these different sources of light. The term Rrs is defined as water-leaving radiance normalized to incident downwelling irradiance and has units of inverse steradian (sr-1). It is not measured in the same manner as benthic reflectance because it only includes a portion of the upwelling stream of light. The parameter Rrs specifically excludes photons that have reflected off the sea surface as glint or from whitecaps and foam that are a property of skylight rather than the water itself. The parameter can be interpreted as a fraction of all photons that have penetrated the water column and emerged from the sea surface in the upward direction only (orthogonal to the sea surface) and is the primary parameter used in processing hyperspectral imagery. As shown in Fig. 3, Most of the radiance measured at a satellite or aircraft is derived from atmospheric scattering and must be removed through atmospheric correction.

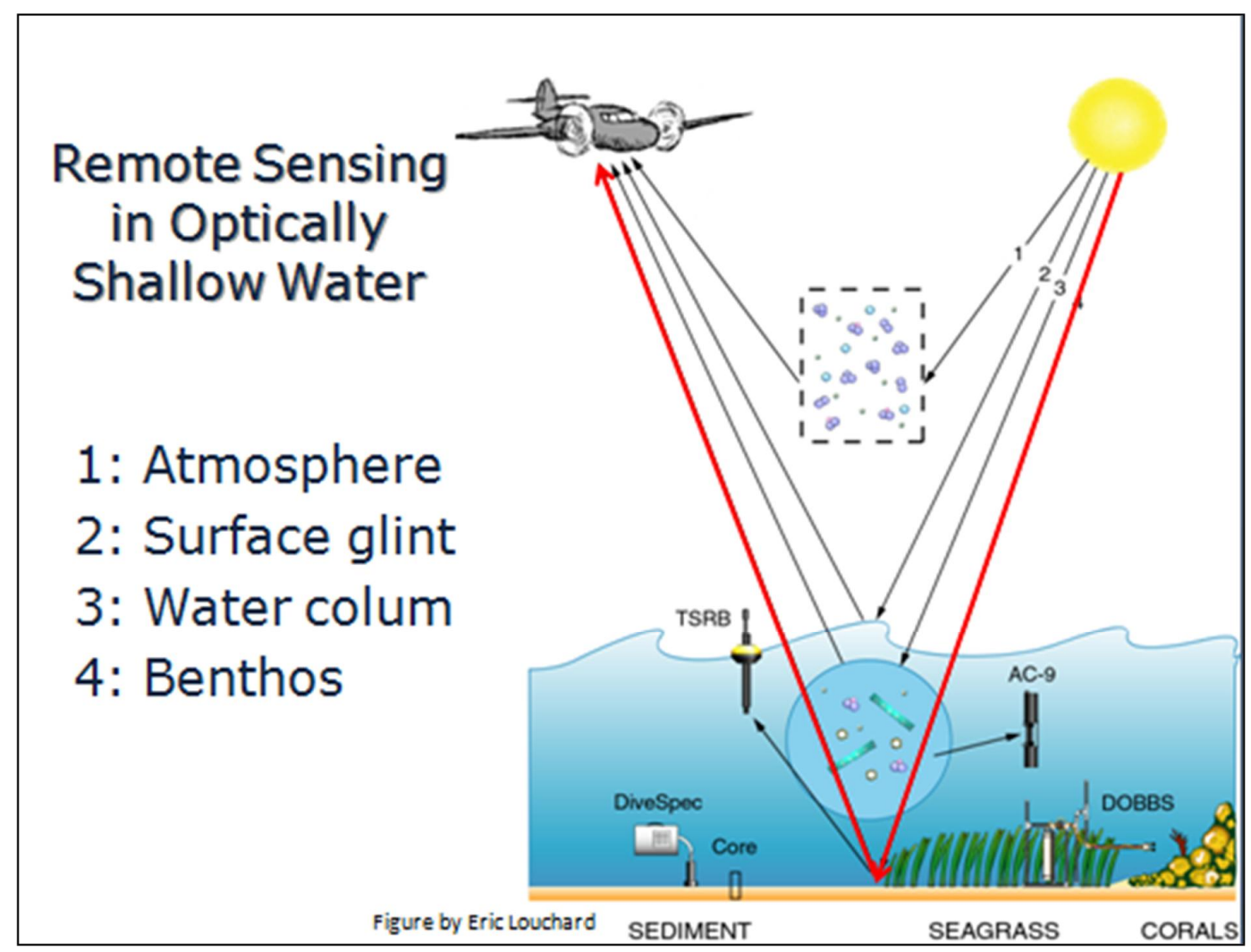

Figure 3.Schematic showing the different sources of photons measured by an imager over optically shallow water. The stream in red is the one used to derive benthic reflectance properties and represents only a small portion of the measured radiance. Various field instruments are depicted for measuring the optical properties of water and the benthos. Figure modified from initial drawing by Eric Louchard. [13]

\section{HYPERSPECTRAL REMOTE SENSING OF SEAGRASS}

Recently, a new high quality imaging spectrometer (PRISM) designed for coastal applications and built by the Jet Propulsion Laboratory, California Institute of Technology (Mouroulis et al. 2008) was used to map seagrass meadows in the turbid waters of Elkhorn Slough, California coastal regime. Seagrass ecosystems are some of the most productive coastal habitats in the world and Zostera marina or eelgrass grows in dense patches up to a few meters depth in the turbid waters of the Slough (Bostrom 2011). This estuary provides critical habitat for many threatened and endangered organisms including marine mammals, sharks, birds, and is facing unprecedented rates of tidal marsh loss over the last 70 years. 
Remote sensing reflectance was measured from a small boat coincident with the PRISM overflights for comparison to the imagery. The PRISM imagery collected in July 2012 provided high quality imagery from $350-1050 \mathrm{~nm}$ collected at $\sim 0.6 \mathrm{~m}$ pixel resolution across the Slough and coastal waters of Monterey Bay. Unlike many approaches, atmospheric correction of the imagery was conducted without using any field spectra using the ATREM model [9] and the resulting data closely matched the field data and required no extra filtering or smoothing (Fig. 4). The spectral shape of water overlying eelgrass meadows is distinct from water in the deeper channel. The deep water had a more peaked spectrum in the $560 \mathrm{~nm}$, whereas the eelgrass had a rounded shape extending throughout the green wavelengths. The pseudo true color RGB image from PRISM shows darker regions along the banks of the Slough that represent the eelgrass. The distinct spectral characteristics of the eelgrass was used to map eelgrass distributions along the Slough at $60 \mathrm{~cm}$ spatial resolution as shown as the green portions in panel 4D.

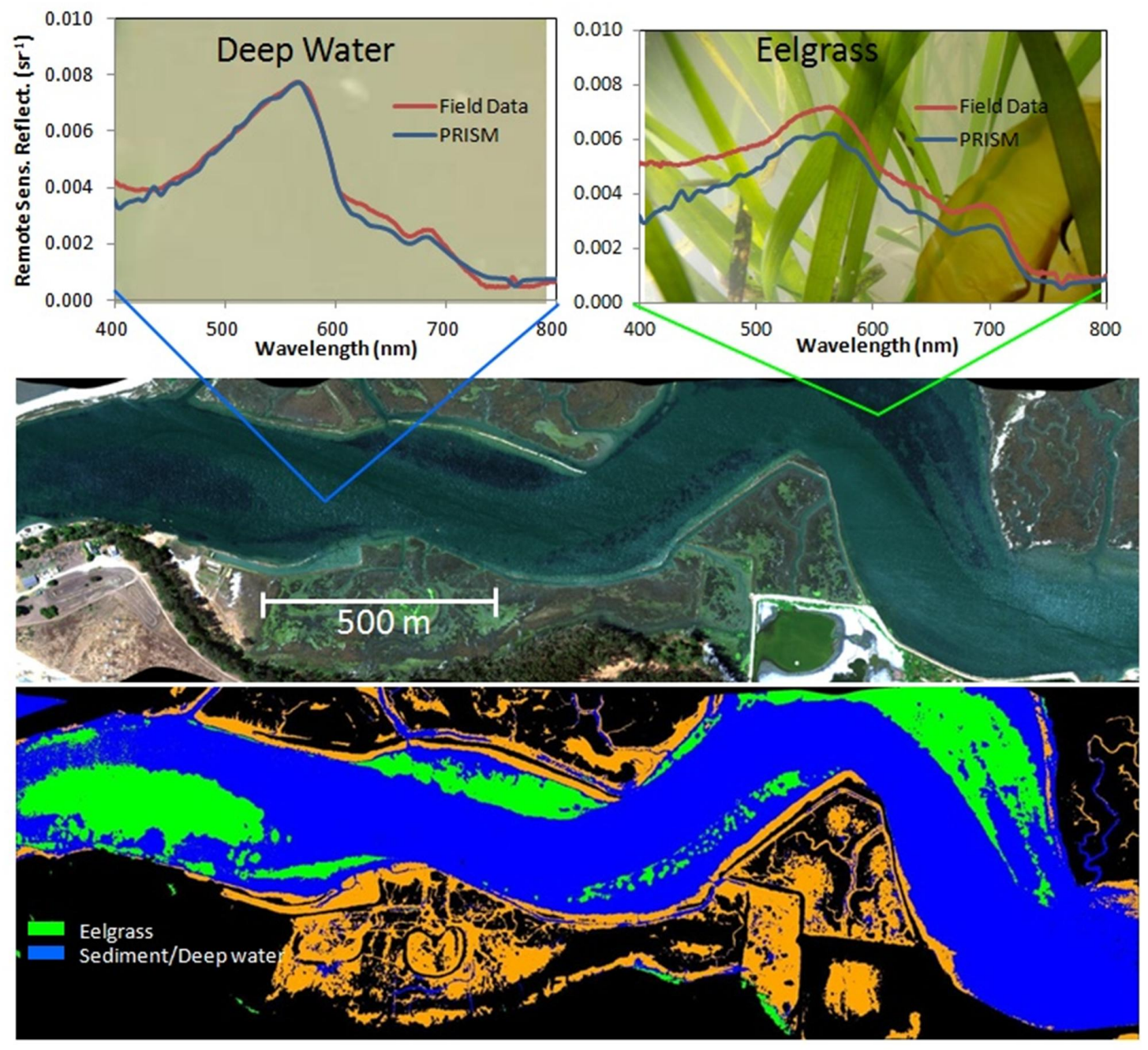

Video 2. The hyperspectral data derived from the PRISM sensor compared well to measurements made in the field over both deep channel water and eelgrass beds (with slight offset due to different tide stages between measurements) and were used to map the distribution of eelgrass beds at $60 \mathrm{~cm}$ resolution in the western portion of Elkhorn Slough. Photos by Eric Heupel and image classification by Brandon Russell, UCONN COLORS Lab 


\section{CONCLUSIONS}

Sensor technology and approaches for conducting hyperspectral remote sensing in coastal ecosystems have advanced over the last decade. Imagery can be collected from satellite, airborne, and underwater platforms with high spectral and spatial resolution and processed to remote sensing reflectance with more accurate atmospheric correction techniques. With appropriate magnitude and spectral shape of image-derived Rrs, many approaches can be used to differentiate the spectral fingerprints of the different benthic constituents and produce maps of water column and benthic properties. High spatial resolution habitat maps provide a tool for monitoring habitat loss over time, as well as attempts to restore valuable coastal wetlands. Baseline maps of seagrass and tidal marsh, for example, can also help to evaluate the efficacy of geoengineering projects such as the underwater sill built as a barrier to slow the flow of the tide and reduce erosion in Elkhorn Slough. Hyperspectral imagery coupled with accurate atmospheric correction can provide a new tool for environmental managers to comprehensively and quantitatively assess growth and decline of coastal habitats.

\section{ACKNOWLEDGEMENTS}

Funding for PRISM and field work was provided by the Ocean Biology and Biogeochemistry Program and the Earth Science Technology Office at NASA. Funding for Florida Bay was provided by the Office of Naval Research under a MURI award. Acknowledgements are given to the Jet Propulsion Lab for PRISM design, fabrication and overflight support, Bo-Cai Gao for atmospheric correction, the UCONN COLORS lab for field collection, Moss Landing Marine Labs for boat operations, and for collaborations with Geir Johnsen at the Norwegian University of Science and Technology (NTNU).

\section{REFERENCES}

[1] H. M. Dierssen, R. M. Kudela, J. P. Ryan, and R. C. Zimmerman, "Red and black tides: Quantitative analysis of water-leaving radiance and perceived color for phytoplankton, colored dissolved organic matter, and suspended sediments," Limnol. Ocean. 51(6), 2646-2659 (2006).

[2] H. M. Dierssen, "Benthic ecology from space: optics and net primary production in seagrass and benthic algae across the Great Bahama Bank," Mar Ecol Prog. Ser 411, 1-15 (2010).

[3] H. M. Dierssen, R. C. Zimmerman, R. A. Leathers, T. V. Downes, and C. O. Davis, "Ocean color remote sensing of seagrass and bathymetry in the Bahamas Banks by high-resolution airborne imagery," Limnol. Ocean. 48(1), 444-455 (2003).

[4] P. J. Mumby, W. Skirving, A. E. Strong, J. T. Hardy, E. F. LeDrew, E. J. Hochberg, R. P. Stumpf, and L. T. David, "Remote sensing of coral reefs and their physical environment," Mar. Pollut. Bull. 48(3-4), 219-228 (2004).

[5] A. G. Dekker, V. E. Brando, and J. M. Anstee, "Retrospective seagrass change detection in a shallow coastal tidal Australian lake," Remote Sens. Environ. 97(4), 415-433 (2005).

[6] S. Phinn, C. Roelfsema, A. Dekker, V. Brando, and J. Anstee, "Mapping seagrass species, cover and biomass in shallow waters: An assessment of satellite multi-spectral and airborne hyper-spectral imaging systems in Moreton Bay (Australia)," Remote Sens. Environ. 112(8), 3413-3425 (2008).

[7] Z. Lee, K. L. Carder, C. D. Mobley, R. G. Steward, and J. S. Patch, "Hyperspectral Remote Sensing for Shallow Waters. 2. Deriving Bottom Depths and Water Properties by Optimization," Appl. Opt. 38(18), 3831-3843 (1999).

[8] A. G. Dekker, S. R. Phinn, J. Anstee, P. Bissett, V. E. Brando, B. Casey, P. Fearns, J. Hedley, W. Klonowski, et al., "Intercomparison of shallow water bathymetry, hydro-optics, and benthos mapping techniques in Australian and Caribbean coastal environments," Limnol Ocean. Methods 9, 396-425 (2011).

[9] B. C. Gao, M. J. Montes, R. R. Li, H. M. Dierssen, and C. O. Davis, "An atmospheric correction algorithm for remote sensing of bright coastal waters using MODIS land and ocean channels in the solar spectral region,"

Geosci. Remote Sens. IEEE Trans. 45(6), 1835-1843 (2007).

[10] H. M. Dierssen and K. Randolph, "Remote Sensing of Ocean Color," in Encycl. Sustain. Sci. Technol. In press, p. 25, Springer-Verlag, Berlin (2013). 
[11] P. Mouroulis, R. O. Green, and D. W. Wilson, "Optical design of a coastal ocean imaging spectrometer," Opt. Express 16(12), 9087-9096 (2008).

[12] G. Johnsen, Z. Volent, H. M. Dierssen, R. Pettersen, M. Van Aredelan, F. Søreide, P. Fearns, M. Ludvigsen, and M. Moline, "Underwater hyperspectral imagery to create biogeochemical maps of seafloor properties," in Subsea Opt. Imaging, Ed. Watson, J. \& Zielinski, O, Woodhead Publishing (2013).

[13] E. M. Louchard, R. P. Reid, C. F. Stephens, C. O. Davis, R. A. Leathers, and T. V. Downes, "Optical remote sensing of benthic habitats and bathymetry in coastal environments at Lee Stocking Island, Bahamas: A comparative spectral classification approach," Limnol Ocean. 48(1), 511-521 (2003). 